\title{
Eessõna
}

Hariduses toimuvad muutused kogu maailmas. Järjest enam otsitakse efektiivsemaid õpetamis- ja kasvatamismeetodeid, millega kaasnevad nii ammu unustatu taastunnustamine kui ka uudsete võtete kasutuselevõtt. Eestis on need protsessid olnud viimastel aastakümnetel tormilisemad seoses ühiskonna üldise arenguga. Need on haaranud enda alla põhi- ja keskkooli (uued riiklikud õppekavad), samuti ülikooli õpetajakoolituse erialad. Põhiküsimuseks, kuidas muudatusi koolis edukalt ellu viia, on kujunenud just õpetajakoolituse sisu ja vormi uuendamine, kuid seda tuleb teha uuringute tulemusi arvestades. Koolides on olukord praegu heterogeenne: siin töötab nii varasema kui ka uuema haridusega õpetajaid, kes erinevad oma uskumustelt ja tegevustelt. Selline mitmekesisus annab uurijatele hea võimaluse jälgida õpetajate uskumuste ja tegevuste osa õpilaste arengus. Seda võimalust kasutavadki praeguse erinumbri autorid ning uurimistulemustest saavad kasu nii õpetajad oma igapäevatöös kui ka ülikoolide õpetajakoolituse õppejõud õppekavade arendamisel ja tulevaste õpetajate koolitamisel.

Ajakirja erinumbri tööde teoreetilise aluse moodustab sotsiaalkultuuriline käsitlusviis (vrd Toomela, 1996, 2003a, 2003b, 2012; Võgotski, 1934; Võgotski \& Luria, 1930/1994). Eeldatakse, et areng ja õppimine on komplekssed - erinevate arenguvaldkondade (nt kognitiivse, sotsiaalse, motivatsioonilise arengu) näitajad mõjutavad üksteist vastastikku, olles omakorda seotud keskkonna (õpilaste puhul eriti kodu ja koolikeskkonna) näitajatega. Keskkond mõjutab arengut normide, reeglite ja uskumuste ning täiskasvanute (kasvatus)tegevuste kaudu, kuid väliselt esitatu internaliseerub lapse aktiivses psüühilises tegevuses, mida vahendavad lapse iseärasused (Kikas, 2003; Nelson, 2003; Toomela, 1996; Võgotski, 1934). Oluline on ka vastupidine protsess, mille puhul lapsed kujundavad keskkonda (nt õpetaja tegevusi; vt Nurmi, 2012). Selline käsitlusviis on sarnane Lars Bergmani ja Margit Wångby sissejuhatavas teoreetilises artiklis kirjeldatud holistlik-interaktsioonilise käsitlusviisiga, mis vaatleb indiviidi tervikuna, milles võib eristada elemente ja mis toimib dünaamiliste (nii indiviidi kui ka keskkonnaga seotud) tegurite koosmõjul. Neis käsitlusviisides rõhutatakse, et indiviidide arengutrajektoorid on erinevad, samuti võib indiviiditi erineda keskkonnategurite roll (vt ka Bergman, Magnusson, \& El-Khouri, 2003). 
Teooriast järeldub, et ideaalis tuleks õpilase arengu mõistmiseks uurida võimalikult erinevaid näitajaid ning nende koosmõju (mis võib otsesest mõjust erineda). Reaalsuses näitajate arvu piiratakse, arvestades konkreetses olukorras olulisimatega. Selles ajakirjanumbris on siiski enamikus artiklites analüüsitud nii õpilase kui ka õpetajaga seotud näitajaid.

Arvesse tuleb võtta ka seda, et arengut ei ole põhimõtteliselt võimalik mõista ristlõikeliste uuringutega. Ainuke arenguliselt informatiivne uurimismetoodika on longituudne ehk pikilõikeline - arenevaid inimesi peab korduvalt uurima psüühiliste funktsioonide arengu alguses, muutumisprotsessi vältel ning lõpuks ka staadiumis, kus funktsioon on formeerunud (vt ka Siegler, 2002). Seetõttu on ka artiklites kasutatud vähemalt kahel mõõtmishetkel kogutud andmeid.

Olukorrast adekvaatsema ülevaate saamiseks on tähtis minna rühmaanalüüsidest edasi ja kirjeldada erinevate indiviidide või indiviidide rühmade arengut. Tänapäeva kasvatusteadused ja psühholoogia toetuvad valdavalt rühmaandmete ja individuaalsete erinevuste analüüsimisele. Paraku ei võimalda inimestevaheliste erinevuste uurimine mõista indiviidi arengut (Toomela, 2007, 2008, 2009, 2010). Andmete analüüsimine nii, et info indiviididele eripäraste tunnuste kohta kaotsi ei läheks, eeldab eriliste indiviidikesksete andmeanalüüsimeetodite kasutamist. Selliseid meetodeid, nende tugevaid külgi ja piiranguid, on täpsemalt kirjeldanud teoreetilises artiklis Lars Bergman ja Margit Wångby. Suuremas osas selle erinumbri empiirilistest töödest on peale variaablikesksete analüüside kasutatud ka indiviidikeskseid analüüsimeetodeid.

Selle erinumbri empiirilistel töödel põhinevad artiklid käsitlevad arengut ja õppimist laias vanusevahemikus alates 1 . klassi õpilastest ja lõpetades õpetajakoolituse üliõpilastega. Uurimise all on õpetajate uskumused ja tegevused ning õpilaste erinevad arenguvaldkonnad.

Kooli algus on oluline aeg laste arengus, siin pannakse alus edasisele akadeemilisele ja sotsiaalsele toimetulekule. Seetõttu tuleb teada, millised uskumused ja tegevused on seotud edukama, millised vähem edukama arenguga. Seda on analüüsitud kahes artiklis. Anna-Liisa Jõgi, Kati Aus ja Eve Kikas kirjeldavad 1. klassi õpilaste matemaatikateadmiste arengut klassides, kus õpetavad noored (algajad, äsja koolis oma tööd alustavad) õpetajad, kes erinevad oma võimekususkumustelt ja tulemusootustelt. Õpetajate võimekususkumused ja tulemusootused mõjutavad seda, millised õpetamismeetodid nad valivad ning kuidas nad õpilaste motivatsiooni suunavad. Uurimusest ilmneb, et reserveeritud uskumustega õpetajatel (neil, kes pigem usuvad võimekuse sünnipärasusse ning ei pea end vastutavaks õpilaste õpitulemuste eest) on enam selliseid õpilasi, kelle nõrgad 
teadmised kooliaasta alguses teiste lastega võrreldes aasta jooksul oluliselt ei parane, ning vähem selliseid õpilasi, kelle nõrgad teadmised kooliaasta alguses paranevad õppeaasta jooksul märkimisväärselt. Optimistlike uskumustega õpetajatel (neil, kes pigem ei usu võimekuse sünnipärasusse ja arvavad, et ópilaste head õpitulemused on tingitud õpetaja tööst) oli vähem õpilasi, kes olid kooliaasta alguses küll heade matemaatikateadmistega, kuid kelle teadmised olid kooliaasta lõpus nõrgemad kui teistel. Töö tulemused näitavad noorte õpetajate võimekususkumuste mõju õpilaste teadmiste arengule ning juhivad tähelepanu tulevaste õpetajate võimekususkumuste ja nende mõju teadvustamisele õpetajahariduses.

Piret Soodla ja Eve Kikas analüüsivad, kuidas erinevad 1. klassi laste lugemisoskus ja -motivatsioon lapsekeskse, õpetajakeskse ja lapsdomineeriva kasvatusstiiliga õpetajate klassides. Lapsekeskse kasvatusstiili korral arvestab õpetaja lapse teadmiste-oskuste tasemega, sellega, et laps konstrueerib oma teadmised ise, kuid tema õpetajana saab seda protsessi toetada. Seevastu õpetajakeskne kasvatusstiil hõlmab õpetaja juhitud tegevusi, suur rõhk on lihtsamate oskuste õppimisel ja kordamisel. Lapsdomineeriva kasvatusstiiliga õpetaja aga annab lapsele palju vabadust ja lähtub sellest, et laps konstrueerib ise, ilma õpetaja abita oma teadmisi. Uuritavas valimis oli enam-vähem võrdselt iga stiili esindajaid. Õpetajate lapsekeskne kasvatusstiil seostus positiivselt ning õpetajakeskne ja lapsdomineeriv stiil negatiivselt nii laste lugemisoskuse kui ka -huviga. Tulemused näitavad seega ühest küljest mehaanilisele kordamisele ja õpetajakesksetele tegevustele toetuva õpetuse ning teisest küljest liigse vabaduse andmise ebaefektiivsust esimeste klasside õpilaste õpetamisel.

Mitmed artiklid käsitlevad õpilaste arengut üleminekul esimesest kooliastmest teise: 3.-5. klassini. Krista Uibu ja Mairi Männamaa analüüsivad õpilaste tekstimõistmist ning selle seoseid nende verbaalse võimekuse ja õpetajate õpetamistegevustega (mehaanilise õpetamise, arusaamise arendamise, teadmiste rakendamisega). Õpetamistegevuste eelistuste alusel eristusid õpetajate profilirühmad ning tekstimõistmise komponentide ja verbaalse võimekuse alusel õpilaste rühmad. Selgus, et tekstimõistmisülesannetes said stabiilselt halvemaid tulemusi need õpilased, kes olid verbaalselt vähem võimekad ja väikese õpetajate eelistusega kõikide õpetamistegevuste suhtes.

Aivar Ots käsitleb seoseid 3.-5. klassi õpilaste kognitiivse arengu ja koolis kogetava heaolu vahel. Uurimuse keskmes on õpilaste psühholoogiline resilientsus (täpsemalt kooliga rahulolu säilitamine kõrge ebameeldivate tundeelamuste taseme korral) ning selle seosed mõistestruktuuri arenguga ja klassiõpetaja kasvatusstiiliga. Uurimistulemustest selgub, 
et kolme aasta vältel arenguliselt hilisemat mõistestruktuuri (st rohkem teadusmõisteid) kasutanud õpilased säilitasid kõrgema negatiivsete elamuste taseme puhul sagedamini rahulolu kooliga. Klassiõpetaja hoolivust väljendavad ja toetavad tegevused seostuvad õpilaste sagedasema rahuloluga ning psühholoogilist ja käitumuslikku kontrolli taotlevad tegevused sagedasema rahulolematusega.

Kahes artiklis käsitletakse ja võrreldakse eesti ja mitme kodukeelega õpilaste arengut. Grete Arro vaatleb ühe- ja mitmekeelsete õpilaste eneserefleksiooni seoseid sotsiaalse toimetulekuga kolmel aastal: 3., 4. ja 5. klassis. Tulemused näitavad, et enesepeegeldusoskus on erinevate kognitiivsete võimetega seotud omadus ning parema enesepeegeldusvõimega lastel on paremad sotsiaalse ja psühholoogilise heaolu näitajad. Mitme- ja ühekeelsete laste enesepeegeldusvõime areng on erinev, ent erinevus vanuse kasvades kaob. Indiviiditasandil ilmnes, et enesepeegeldusvõime võib olla mitme- ja ühekeelsete laste rühmades kohanemisega erinevalt seotud.

Kristina Seepter käsitleb koos õppivate 3.-5. klassi eesti- ja kakskeelsetest kodudest pärit õpilaste akadeemiliste teadmiste arengut, täpsemalt seda, kuidas need ópilased realiseerivad enda vaimse võimekusega seotud potentsiaali matemaatikas ja eesti keeles ning millised klassi õpikeskkonnad toetavad õpilaste arengut ja millistes õpikeskkondades on õpilastel probleeme. Kui 5. klassis olid matemaatikateadmised kakskeelsetel õpilastel jõudnud umbes samale tasemele kui samas õpikeskkonnas õppivatel eestikeelsetel lastel, siis eesti keele mõistmises püsis kakskeelsete rühm eestikeelsetega võrreldes kõigil kolmel aastal (3.-5. klass) oluliselt madalamal tasemel. Samas ei olnud kõik kakskeelsed õpilased kehvemate akadeemiliste tulemustega. Võimekusele mittevastav madalam akadeemiline tase iseloomustas just keskpärase võimekusega kakskeelseid lapsi, seda eriti keskmisest madalama võimete tasemega ja homogeensetes klassides.

Algkoolist põhikooli liikudes muutub õpitav keerulisemaks ja abstraktsemaks. Just põhikoolis teravnevad motivatsiooniga seotud probleemid ja ilmnevad kehvadest õpioskustest tulenevad raskused. Õpetaja võiks neid probleeme märgata ja õpilasi sobival viisil toetada, kuid alati seda ei tehta. Kati Aus, Grete Arro, Anna-Liisa Jõgi ja Elina Malleus käsitlevad hariduskontekstis suhteliselt vähe uuritud õpikäitumist 8. klasside õpilaste akadeemilist prokrastineerimist (õpikohustuste täitmise edasilükkamist) ja seda, kuivõrd õpetajad sellist probleemset käitumist märkavad. Tulemustest ilmneb, et õpilaste ja õpetajate hinnangud ei lange alati kokku ning õpetajad näevad prokrastineerijatena pigem vähem võimekaid õpilasi, olenemata sellest, kas õpilane ise peab end pro- 
krastineerijaks või mitte. Samuti tõid ópetajad prokrastineerijatena esile pigem keskmisest ekstravertsemaid lapsi. Tulemused lubavad järeldada, et õpetajatel on raske tuvastada võimekamate ja introvertsemate õpilaste eneseregulatsiooniprobleeme.

Katrin Poom-Valickise ja Erika Löfströmi artikkel keskendub sellele, kuidas üliõpilased õpetajaks kujunevad. Mittestruktureeritud intervjuudes kasutati taustinfona ja intervjueeritavate mälutugedena kolmel õpinguaastal üliõpilaste kirja pandud metafoore õpetaja rolli kohta ning küsimustiku abil kogutud infot. Tulemustest selgub, et õpingute alguses oli valimisse kaasatud üliõpilastel õpetaja tööst naiivne ettekujutus, mis toetub isiklikule varasemale koolikogemusele. Arusaamad õpetaja tööst ja rollist muutusid õpingute jooksul komplekssemaks, õpetajakoolituse lõpus väärtustati enim pedagoogilist asjatundlikkust. Kõige tugevamalt mõjutas tulevase õpetaja arusaamade kujunemist pedagoogiline praktika.

Viimases osas võtab Mati Heidmets vaatluse alla kaks rahvusvahelist uuringut: PIIAC (Programme for the International Assessment of Adult Competencies) ja PISA (Programme for International Student Assessment), milles võrreldakse eri maade täiskasvanute ja kooliõpilaste elulisi oskusi, nt matemaatika, probleemilahendamise ja tekstimõistmisega seotud oskusi. Need pole pikiuuringud ning neis ei käsitleta arengut, kuid need annavad hetkepildi sellest, millised on mõõdetud oskused meie kooliõpilastel ja täiskasvanutel võrdluses teiste maade samas vanuses inimestega.

Kokkuvõtteks, selles erinumbris analüüsitakse eri vanuses õpilaste ja üliõpilaste arengut ning õppimist, seejuures ei keskenduta mitte ainult indiviididele, vaid ka neid ümbritsevale keskkonnale. Uurimustes rakendatakse erinevaid andmekogumismeetodeid (küsitlemist, vaatlemist, intervjueerimist, testimist, küsimustike täitmist) ja andmeanalüüsimeetodeid (variaabli-, indiviidikeskseid meetodeid). Need kujutavad endast küll üksnes fragmente, kuid kirjeldavad hästi seda, mis toimub praegu Eesti koolis ja ülikoolis. Loodetavasti ärgitavad artiklid uurijaid selles valdkonnas edasi mõtlema, samuti annavad õpetajatele ideid, mida nad saavad oma töös kasutada.

Eve Kikas ja Aaro Toomela 


\section{Kasutatud kirjandus}

Bergman, L. R., Magnusson, D., \& El-Khouri, B. M. (2003). Studying individual development in an interindividual context. London: LEA.

Kikas, E. (2003). Constructing knowledge beyond senses: Worlds too big and too small to see. In A. Toomela (Ed.), Cultural guidance in the development of the human mind (pp. 211-227). Westport, CT: Ablex Publishing.

Nelson, K. (2003). Making sense in a world of symbols. In A. Toomela (Ed.), Cultural guidance in the development of the human mind (pp. 139-161). Westport, CT: Ablex Publishing.

Nurmi, J.-E. (2012). Students' characteristics and teacher-child relationships in instruction: A meta-analysis. Educational Research Review, 7(3), 177-197. http://dx.doi.org/10.1016/j.edurev.2012.03.001

Siegler, R. S. (2002). Microgenetic studies of self-explanations. In N. Granott \& J. Parziale (Eds.), Microdevelopment: Transition processes in development and learning (pp. 31-58). New York: Cambridge University. http://dx.doi.org/10.1017/CBO9780511489709.002

Toomela, A. (1996). How culture transforms mind: A process of internalization. Culture and Psychology, 2(3), 285-305. http://dx.doi.org/10.1177/1354067X9600200305

Toomela, A. (2003a). Culture as a semiosphere: On the role of culture in the culture-individual relationship. In I. E. Josephs (Ed.), Dialogicality in development (pp. 129-163). Westport, CT: Praeger.

Toomela, A. (2003b). Development of symbol meaning and the emergence of the semiotically mediated mind. In A. Toomela (Ed.), Cultural guidance in the development of the human mind (pp. 163-209). Westport, CT: Ablex Publishing.

Toomela, A. (2007). Culture of science: Strange history of the methodological thinking in psychology. Integrative Psychological and Behavioral Science, 41(1), 6-20. http://dx.doi.org/10.1007/s12124-007-9004-0

Toomela, A. (2008). Variables in psychology: A critique of quantitative psychology. Integrative Psychological and Behavioral Science, 42(3), 245-265. http://dx.doi.org/10.1007/s12124-008-9059-6

Toomela, A. (2009). How methodology became a toolbox - and how it escapes from that box. In J. Valsiner, P. Molenaar, M. Lyra, \& N. Chaudhary (Eds.), Dynamic process methodology in the social and developmental sciences (pp. 45-66). New York: Springer. http://dx.doi.org/10.1007/978-0-387-95922-1_3

Toomela, A. (2010). Methodology of idiographic science: Limits of single-case studies and the role of typology. In S. Salvatore, J. Valsiner, J. T. Simon, \& A. Gennaro (Eds.), Yearbook of idiographic science (Vol. 2/2009, pp. 13-33). Rome: Firera \& Liuzzo Publishing.

Toomela, A. (2012). Guesses on the future of cultural psychology: Past, present, and past. In J. Valsiner (Ed.), The Oxford handbook of culture and psychology (pp. 9981033). New York: Oxford University Press.

Võgotski, L. S. (1934). Myshlenije i rech. Psikhologicheskije issledovanija. Moskva: Gosudarstvennoje Social'no-ekonomicheskoje Izdatel'stvo.

Võgotski, L. S., \& Luria, A. (1994/1930). Tool and symbol in child development. In R. van der Veer \& J. Valsiner (Eds.), The Vygotsky reader (pp. 99-174). Oxford: Blackwell. 